\title{
Lima y su modernidad olvidada
}

JAVIER PRotzel

In memoriam

Gonzalo Portocarrero

\section{INTRODUCCIÓN}

Las formas de la memoria colectiva son de variable consistencia y nitidez. Para mucho(a)s esta dura actualmente apenas un poco más de lo que permanecen los acontecimientos en las páginas de los diarios o en las pantallas de teléfonos y televisores. Aunque se trata de un fenómeno mundial, quiero referirme particularmente aquí a Lima, más que al Perú. La inmensidad de la ciudad, su anomia, su heterogeneidad e intensa movilidad han recortado la vieja conciencia de pertenencia a barrios o distritos longevos, cimentada por la tradición local. Y a escala de su conjunto, la metrópolis dista en mucho de contar con una memoria histórica mínimamente unitaria que permita a sus ciudadanos reconocer su identidad en ella, salvo por acontecimientos extraordinarios. Si quienes nos interesamos en estos asuntos miramos hacia atrás, percibimos que en nuestra historia urbana hay etapas de luz y de oscuridad. Algunas fueron iluminadas por ciertas obras $\mathrm{u}$ acontecimientos cuya narración, aunque borroneada, sobrevivió y llegó al presente. Otras pasaron al olvido y pese a que sus huellas subsisten, siguen inadvertidas. Me propongo en este ensayo una revisión crítica de algunos aspectos de la Lima del segundo cuarto del siglo pasado, quizá el único y corto momento en que la capital peruana parece vencer sus dificultades para representarse a sí misma como un conjunto, el de alcanzar la ilusión de ser la metrópoli criolla. Ese periodo hoy soslayado cimentó un proyecto de tránsito (nunca acabado) de una ciudad encapsulada en su criollismo que se convertía en metrópoli nacional, anfitriona obligada de 'todas las sangres' llegadas en los procesos de migración interna. La realidad social de un país pobre y centralista puso en crisis aquel proyecto culturalmente hegemónico.

Me estoy refiriendo más a lo urbano que a la ciudad, distinguiendo las prácticas materiales y simbólicas de los usuarios de los volúmenes edificados y los espacios físicos habilitados para circular, según lo ha hecho Armando Silva (1992). Huelga detallar que toda construcción arquitectónica es al mismo tiempo un trabajo funcional de ingeniería y una elaboración simbólica, aunque de esto último muchos no sean conscientes. Y tanto más si la ciudad que se moderniza se caracteriza antes por un cambio en la 'vida mental' de sus habitantes, tomando la expresión de Simmel (2003 [1902]) que 
por su superficie y población aumentadas per se. He compuesto este ensayo basándome en una variedad de textos que me propuse vincular entre sí, así como en mis propias observaciones y estudios previamente realizados.

\section{LA CIUDAD QUE SE FUE}

Una breve recapitulación histórica. Desde antes de la Guerra del Pacífico (1879-1883) ya soplaban en Lima vientos de modernización. El auge guanero había traído el afán por el ornato y la renovación de la ciudad, el primer ciclo de varios otros que le sucederían hasta la década de 1940 (Ramón Joffré, 2004, pp. 9-33). Derribadas las antiguas murallas (1869) se buscó un nuevo trazo urbano surcado por vías más anchas y la ampliación del espacio para edificar viviendas. Este modelo urbanístico radial, traído de Europa, consistía en diseñar superficies amplias como puntos de referencia centrales (plazas, parques) de los cuales irradiaban avenidas que se intercomunicaban entre sí. Esos nodos cubrían espacios vastos, llamados monumentales precisamente por estar ornados con grandes esculturas conmemorativas de héroes, guerras y alusiones a la gloria de la nación. Como ha señalado Natalia Majluf (1994, p. 30), existió una equivalencia entre escultura y progreso. Las formas físicas de la ciudad cumplían por ello un rol de representación simbólica de la narrativa y la celebración de un Perú aún joven. Por ello, si "en Europa el mármol y el bronce podían ser sinónimos de una venerable tradición que llevaba hasta los orígenes de la civilización en la antigüedad clásica, ... para el Perú del ochocientos fueron sinónimos del futuro" (Majluf, 1994, p. 31). Una muestra temprana de ello fue la creación de la plaza Dos de Mayo (1874) en cuyo centro se colocó una gran escultura en homenaje al combate victorioso del 2 de Mayo contra la flota española ocho años antes. La idea de modernidad calaba en las élites económicas agrupadas en el Partido Civil, las cuales consideraban inviable una ciudad con solo una minoría de ciudadanos políticamente hábiles, muchos proclives al rentismo, y una afición extendida a los juegos de azar en todos los sectores sociales. Un parecer que se acentuó con el empobrecimiento posterior a la guerra al voltearse las miradas hacia Europa y Estados Unidos, movidas por los valores de la industria y de la educación. La herencia colonial -la prolongación republicana de la estructura social estamental del virreinato, de la beatería y el analfabetismo- vigente varias décadas tras la Independencia, entraba en crisis. El crecimiento exportador durante la República Aristocrática (1895-1919) provocó un aumento considerable de la población de Lima (entre 1876 y 1908 la población capitalina se incrementó de 100516 a 138134 habitantes), favoreciendo la expansión de la ciudad radial y el trazo de nuevas vías de circulación jalonadas por monumentos. Así, el paseo Colón (llamado antes Nueve de Diciembre) data de 1899, la avenida La Colmena de 1899, la plaza Bolognesi de 1905 y la Plaza Mayor es renovada en 1901 (Ramón Joffré, 2004, pp. 19-20). 
La nostalgia de José Gálvez en Una Lima que se va (1921) fue seguramente tomando el cuerpo de un fenómeno social a medida que la urbe se expandía y la gente acomodada se codeaba menos con los pobres. Como ocurre en las sociedades que se enriquecen, las figuras del pasado se achicaron, luciendo modestas y afectuosas. Progresivamente apareció una utopía retrospectiva (noción que le debo a Julio Ortega) en el imaginario urbano, plasmado en obras como la de Gálvez, quien vivió la pobreza y la ruina de la posguerra, sin que eso le impidiera escribir que

la lamentable conciencia de los cambios sufridos, de las ilusiones que no retoñarán jamás, comprende fríamente que al vibrar de las mismas canciones el corazón no palpitará como la vez primera, que ya se cree de otro modo, que se ríe de manera diferente, y, aunque parezca mentira, hasta se llora diversamente de lo que se lloraba antaño. (Gálvez, 1921, p. 125)

Me interesa resaltar que en el discurso del criollismo se asocian tres elementos: una remembranza bien idealizada, una necesidad de preservar lo 'auténtico', y cierto populismo que acerca a las élites y a la plebe en torno a prácticas simbólicas y creencias, pero subordinándola. El retroceso de esa mentalidad localista conservadora convivió con la nueva en las etapas de mayor innovación en la vida urbana, los once años de la presidencia de Leguía (1919-1930). Los tres ejes viales tendidos en ese régimen -avenidas Leguía (rebautizada Arequipa) ${ }^{1}$, Brasil y Progreso (llamada Colonial posteriormente)alentaban el éxodo hacia las nuevas urbanizaciones, aunque el que llevaba a Miraflores y Barranco vía la mesocrática Santa Beatriz y San Isidro resultó ser el más notable y publicitado al marcar la principal ruta de la gente adinerada. A lo largo de la avenida Arequipa aparecieron construcciones de diversos tamaños y estilos que variaban conforme uno se aproximaba al sur.

Primaba la idea de una ciudad de edificaciones rodeadas por amplias zonas verdes, con servicios de transporte público a distancias mayores dispuestos sobre vías extensas. El modelo de la ciudad radial era reemplazado por uno expansivo y de origen anglosajón, el de la Garden City ${ }^{2}$ suburbana para clases altas y medias cuya estela llegó hasta fines de la década de 1950. La adopción de costumbres y deportes de origen británico (ciclismo, fútbol, regatas, tenis) marcó un cambio en las élites de la generación de posguerra. En Nuestra pequeña historia [1930] es el mismo Gálvez quien relata haber sido en 1894 "uno de los trece muchachos [que] con parlamentaria seriedad en el atrio del viejo templo de San Pedro" (1966, p. 220) fundó el club Union Football, el primero en usar esa palabra.

1 Para mayor información véase blog.pucp.edu.pe/blog/juanluisorrego/2011/ 04/03/la-avenida-leguiahoy-arequipa/

2 Las Garden cities fueron una propuesta urbanística de inicios del siglo XX formulada en Inglaterra por Ebenezer Howard. Postulaba modos de vida saludables y cómodos mediante la edificación de casas baratas en localidades provistas de verdura en las periferias metropolitanas, pero equipadas con transporte y servicios propios. 
La idea de Garden City se plasmó en el denominado chalet (equivalente a casa campestre en los Alpes) que se codearía con los caserones de la década de 1930. Antonio Zapata (1990, p. 165), sostiene que de esa década en adelante el chalet designó al género íntegro de viviendas unifamiliares fuera del centro de Lima, y no un estilo singular. Lo interesante del chalet se condensa en dos observaciones. Primero, la sustitución de los antiguos materiales de construcción (adobe, quincha, madera) por los de material noble (cemento, ladrillo, fierro); y luego, una distribución interna de las edificaciones que mostraba rasgos de un estilo de vida heredado de la Colonia. Esa convivencia de lo antiguo con lo moderno es bien captada por José Diez-Canseco en su novela Suzy. Nos muestra adolescentes anglófilos que languidecen en un Barranco aun de potreros polvorientos y de "desiertas callejas por las que discurren pesadas carretas, alígeras carretas, levantando con el restallar de los látigos el vuelo de las palomas" (2004 [1930], p. 11).

¿Cuánto había de verdaderamente 'moderno' en esos cambios limeños? De 1920 a 1940 en Lima la población se duplicó, y el área urbana de la Lima compacta de 1931 se expandió al sur y al oeste aumentando su superficie de 2037 hectáreas a 5630 en 1940 (Calderón, 2005, p. 65). Aumentó la desigualdad por habitante del área construida, si se compara la amplitud de los nuevos distritos del sur y suroeste con la creciente concentración y tugurización en el Cercado y el Rímac ${ }^{3}$. Las distancias sociales y el acceso desigual a las innovaciones implicaban nuevas formas de conocimiento del Otro; disminuía el antiguo vínculo de las calles estrechas compartidas y plazuelas del espacio público. Ahora bien, la oposición tradición/modernidad es un fresco con mucha variedad de grises. En el Cercado quedaron huellas que llevaban al siglo anterior, como es el caso de Barrios Altos. Pese a que la población de esa zona cambió al irse reciclando con el desplazamiento de los sectores medios al sur, las primeras hornadas de inmigrantes la densificaron y mantuvieron la vida barrial con su intensa interacción callejera, personalidad e insularidad.

Con el paso del tiempo la población de sus numerosas casas de vecindad, callejones y solares se multiplicó acentuando la continuidad entre espacios privados y públicos en esa zona con predominio de viviendas alquiladas y subalquiladas (Panfichi, 2013, pp. 85-86).

A medida que la herencia colonial se encogía, crecía la lógica de las diferencias de clase basadas en el dinero. Desde la óptica de las mentalidades, la vida en la ciudad modernizada consistía en la activación de un nuevo proceso de construcción de representaciones colectivas, desvinculado de la tradición oral y sus voces callejeras. En los

3 Véase http://cammp.ulima.edu.pe/edificios/barrio-obrero-n3/ 


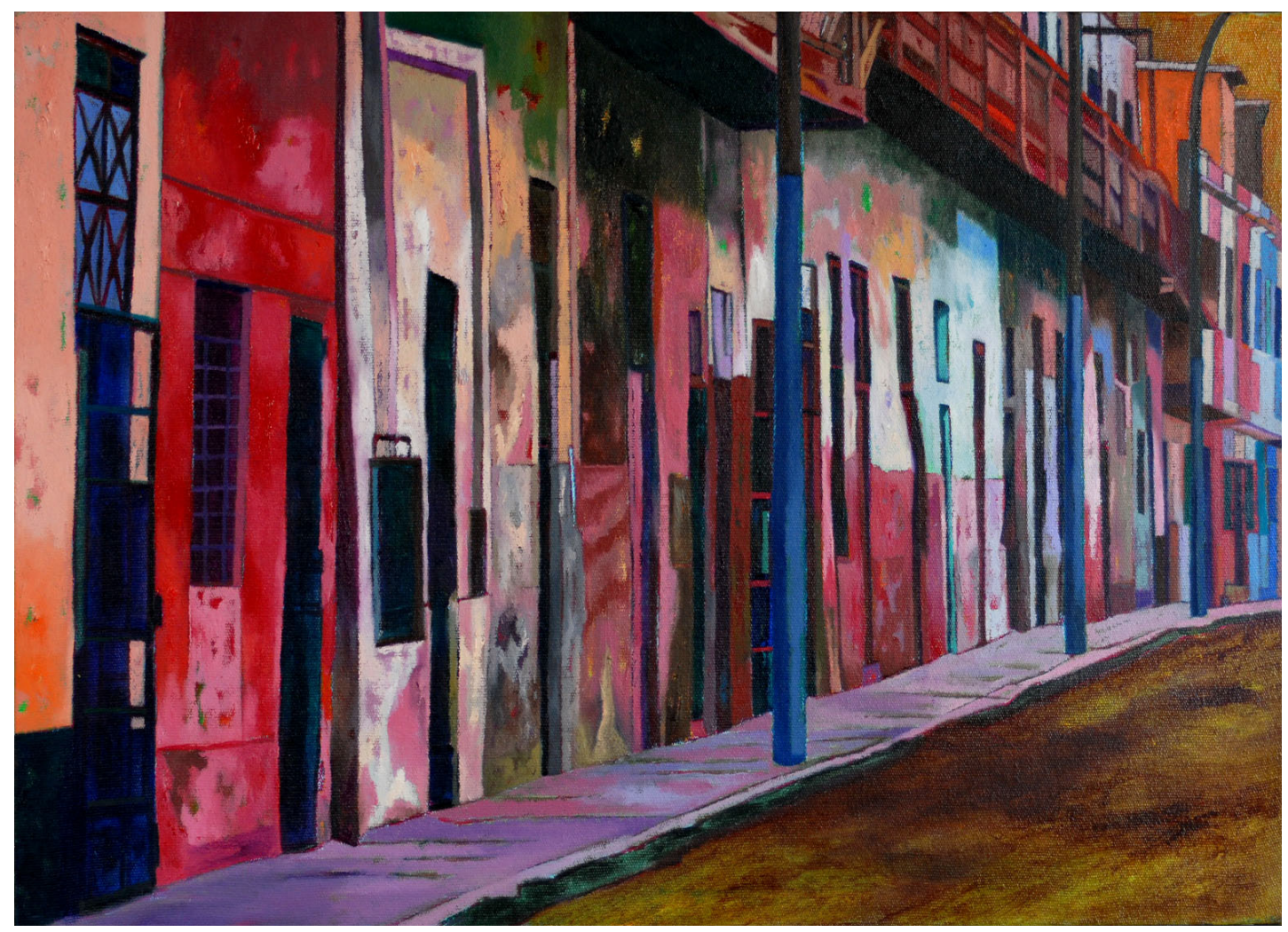

Enrique Polanco. Paisaje urbano (Noe) de la serie Camina el autor (homenaje a Huamán Poma) (2016). Óleo sobre tela y collage, $1 \mathrm{~m} \times 70 \mathrm{~cm}$

años 1940 esto afectó a las clases medias posleguiistas debido a la disminución de su poder adquisitivo respecto a los obreros y artesanos de las inferiores. Las empujó hacia estrategias simbólicas más difíciles, fijadas en lo cultural como indicador de 'decencia': educación, vestimenta, acento en el habla; en general, poder aparentar gracias al incipiente mercado de bienes de consumo importados, de publicidad y cine. Subyacía un elemento discriminador en ese afán por introducirse en redes de interacción social más altas, un racismo inter pares en una sociedad de creciente mestizaje biológico, entre distintos matices jerarquizados de tez facial. Así, se reeditaba en versión poscolonial la antigua práctica del virreinato del "blanqueamiento" intergeneracional (Portocarrero, 2013).

\section{PROYECTO URBANÍSTICO Y GOBERNANZA DISCIPLINARIA}

¿Había entonces alguna visión consistente de la modernidad urbana con vocación de generar nuevas representaciones colectivas? Entre los arquitectos, definitivamente, aunque no sin debates. Esas concepciones remiten a tres tipos de discurso: el de un aggiornamento academicista, el del movimiento moderno expresado en la Agrupación 
Espacio, y el del Estado industrialista disciplinario. Para Wiley Ludeña, quien lo ha investigado $(2003,2006)$, la inquietud por el trazo y desarrollo de la ciudad se remonta a muy atrás, y atraviesa la década de 1930 con la construcción de barrios obreros, restaurantes populares, refectorios escolares, etcétera (Drinot, 2016) y llega a su cénit en los años 1940, “década prodigiosa” según Ludeña.

Empero, para los sectores privilegiados la adhesión a la vida moderna no significaba renunciar a los emblemas del pasado sino transmutarlos en un discurso academicista mistificador. Los trazos nuevos de la ciudad jardín orientados hacia el sur y suroeste venían acompañados de un giro estilístico arquitectónico conciliador con los viejos imaginarios: diseños neoincaicos y neoperuanos de una estética ecléctica que combinaba sobre las fachadas de inmuebles públicos y grandes residencias privadas formas coloniales y academicismo clásico, en algunos casos con bajorrelieves geométricos precolombinos de aspecto pétreo para obtener una síntesis presuntamente 'peruana'. Las connotaciones pasatistas y de poderío de este estilo remiten a cierto tiempo pretérito indefinido que eterniza la memoria del pasado europeo señorial, el abolengo del imperio incaico y la fuerza del hombre vernáculo. Estas hibridaciones acercan el elemento indigenista a cierto imaginario de pompa virreinal proponiendo su visión para el Perú de la época: una metonimia del mestizaje que 'crea' - desde Lima - lo que Mirko Lauer denominó una "categoría universal alterna" para lo peruano (1982, pp. 111-113). En esta se disuelve y niega a la vez las especificidades de las realidades indígenas al anexárseles como elemento genérico a las composiciones eclécticas.

Con o sin 'citas' de lo indígena, ¿cómo no tendría esta emulsión netamente limeña fuerza ideológica teniendo de paradigma al nuevo Palacio de Gobierno mismo (1938), concluido por Ricardo de Jaxa-Malachowski? Este arquitecto de origen polaco tuvo también a su cargo el diseño y construcción del Palacio Arzobispal, del nuevo Palacio de Gobierno (1924), la terminación del Palacio Legislativo (1938) y del Club Nacional (1929), entre muchas otras obras. Concuñado del presidente Benavides, su versatilidad y rigor le permitieron abrazar extremos estéticos como el precolombino de Tiawanako para el Museo Nacional de Cultura Peruana (1924) y el francés Segundo Imperio del imponente Edificio Rímac al inicio del Paseo de la República ${ }^{4}$. Otros arquitectos notables que alternaron con él -Manuel Piqueras Cotolí, Emilio Harth Terré, Rafael Marquina- contribuyeron igualmente a la fama de la llamada ciudad jardín, diseñando e interviniendo espacios, edificando dependencias de la administración pública que connotasen un Estado 'fuerte' y dotado de equipamientos públicos; hitos marcados a lo largo del tiempo hasta 1950 de una expansión avizorada como camino hacia la condición de metrópoli. La arquitectura y el urbanismo materializaban la ideología

4 Véase http://historiadordelperu.blogspot.com/2012/01/el-edificio-rimac.html 
prevaleciente sobre la ciudad; las corrientes neocolonial y neoperuana pretendían ser identificadores colectivos fundadores de un Perú moderno que no rompía con el pasado.

A fines de la década de 1930 vino un cambio. El movimiento moderno en urbanismo y arquitectura se asentó en Lima, gracias a la defensa que hizo el influyente arquitecto Luis Miró Quesada Garland, autor de Espacio en el tiempo, la arquitectura como forma cultural (2014 [1945]), un conjunto de ensayos de afirmación del arte abstracto, de una arquitectura de diseños ortogonales, austeridad ornamental, luz exterior en los interiores, verdura y funcionalidad, así como de un urbanismo renovado, siguiendo los principios de la Bauhaus berlinesa. Lo singular de la estética de Miró Quesada es su purismo hegeliano, según el cual el arte es la materialización de la Idea. La Idea, al ser 'para sí', carece de determinaciones histórico-sociales: la pureza de la forma y la volumetría serían autónomas respecto al gusto, validarían el "arte por el arte" y además jalonarían el derrotero de la Historia como realización de la Idea. El discurso de Miró Quesada asentó la arquitectura moderna en el medio universitario al proponer un urbanismo funcional al país en una época en que el progreso técnico "ha cambiado la manera de pensar" (2014 [1945], p. 40). Por ello, recusa el tradicionalismo, dada la "necesidad social absoluta de una arquitectura nueva y evolucionada que rompa con una práctica de hacer obra fácil". Estas ideas propinaron un golpe a los manierismos mencionados y en general a la retórica indigenista, traduciendo la actitud innovadora de los artistas e intelectuales que habrían de constituir la Agrupación Espacio (1947) bajo el liderazgo de este autor. La Agrupación Espacio reivindicaba para el Perú una consciencia universalista (antónima de una nacionalista) afirmando que lo moderno no conoce de fronteras, pues Miró Quesada - no toda la Agrupación Espacio- pulió una definición culturalmente desarraigada y espiritualista de lo moderno en una época de fuerte debate político e ideológico ${ }^{5}$.

El tercer tipo de discurso es el del Estado, componente de las intensas luchas por el poder de ese periodo. La germinación de sectores medios durante tiempos de Leguía trajo posteriormente en una parte de estos posiciones independientes de enunciación política frente a los grupos superiores. Actitud 'pensante' frente al país y una disposición a pactar con las organizaciones obreras ya entonces movilizadas (Stein, 1980, p. 96). La bullente belicosidad política del aprismo y del comunismo tras la elección del comandante José Luis Sánchez Cerro (1931), seguida de la insurrección de Trujillo (1932) y el asesinato de Sánchez Cerro (1933), modificó la narrativa de la modernidad peruana. Instalado en Palacio de Gobierno gracias al sanchezcerrismo, el general Óscar R. Benavides fue declarado presidente para emprender un proyecto autoritario

5 La casi totalidad de las ilustraciones fotográficas y croquis que ilustran Espacio en el tiempo son de obras ajenas no realizadas en el Perú a lo largo de distintas épocas. El propósito de Luis Miró Quesada ha sido probablemente deliberado para significar el rebasamiento de tiempos y espacios por el arte. 
de gobernanza. La persecución de apristas y comunistas le facilitó el desarrollo de políticas públicas que mantuvieran bajo sus riendas el potencial explosivo de las masas. El gobierno debía - así lo ha estudiado Paulo Drinot (2016) - cumplir con una "misión civilizatoria" de "redimir" a un pueblo considerado "bárbaro", proveyéndolo de fuentes de trabajo, viviendas, educación, nutrición y salud. El Tercer Militarismo intentó establecer un orden político corporativista emparentado con el fascismo (Molinari Morales, 2017), donde cada ciudadano debe estar adscrito a una colectividad, cuyo ejemplo sería la ampliación de la ciudad mandando edificar barrios obreros. En cierto modo, la clase obrera fue institucionalmente constituida por el régimen de Benavides a través de una poderosa Sección de Trabajo ministerial que funcionaba como un dispositivo de vigilancia (Drinot, 2016, pp. 103-105). La finalidad general de esta tecnología de gobierno fue "racializar" a la clase obrera, entendiéndose por ello una "domesticación" de la mayoría mestiza e indígena de entonces, identificada con la pobreza y el atraso. Los cinco barrios obreros construidos de 1936 a 1939 materializaron una doctrina desplegada en una estrategia que incluía provisión de empleo y seguro médico ${ }^{6}$, así como la puesta en marcha de varios restaurantes bajo responsabilidad de la Junta Pro Desocupados. La Dirección de Previsión Social contabilizó en 1938 más de ocho millones y medio de almuerzos servidos en estos establecimientos, organizados y atendidos bajo condiciones de estricta disciplina.

Al respecto es ilustrativo marcar un contraste refiriéndonos a la comida china. Desde fines del siglo XIX, y ya liberados de sus contratos agrícolas, la mayoría de los inmigrantes chinos se estableció en Lima (casi el 11 \% de la ciudad en el censo de 1908). Fueron objeto de una severa racialización que abominó de su fenotipo y costumbres, calificándoseles de "raza degenerada", sucia y viciosa (Rodríguez Pastor, 1995). Muchos de entre ellos vivían de las fondas que abrieron en épocas de carestía de alimentos con gran éxito de su comida cantonesa. Pese a los denuestos lanzados por las élites, en 1921 apareció en la calle Capón el Kuong Ton, el primer chifa para comensales burgueses (Chuhué, 2016) de modo tal que la creación de restaurantes populares, década y media más tarde, pareció ser una medida higienista disuasiva contra una alimentación presuntamente insalubre como la asiática.

\section{MÚSICA CRIOLLA Y CULTURA MODERNA}

Más acá del autoritarismo político y del crecimiento físico de la urbe, están los cambios culturales de esa época. Criollismo es un significante flotante que a lo largo del tiempo

6 En agosto de 1936 se creó por Ley el Seguro Social Obrero Obligatorio, administrado por una Caja Nacional. Dos años después se construyó el Hospital Obrero, inaugurado en 1941. Su nombre actual es Guillermo Almenara Yrigoyen, su primer director (Essalud, 2016, pp. 4-5; Tauro del Pino, 2001, p. 100). 
y en sus sucesivos avatares hasta la quinta década del siglo pasado fue identificado con lo 'peruano'. Al menos entre los costeños, pues los intelectuales limeñistas nostálgicos -Palma, Gamarra, Gálvez, Porras - reticentes hacia las modas extranjeras veían disolverse en el aire las sólidas tradiciones que defendieron. Los pobres, los jaranistas, los habitantes de los callejones se convierten en los 'verdaderos' depositarios de las aguas empozadas del pasado. El habla, el clima de fiesta y molicie, los espacios de encuentro, la culinaria, la música lo criollo se opone a lo foráneo. Irónicamente, lo criollo se esencializó a medida que su substancia se reciclaba conforme algunos de sus componentes se hundían en el olvido y otros le eran incorporados. Según se le mire, lo criollo es entonces un constructo discursivo, un estado de ánimo o una posición ideológica con respecto a determinados bienes simbólicos. Así, de los años 1930 a 1950 lo criollo se sedimenta al calor de las luchas políticas para identificársele con el mestizaje, una peruanidad distinta a la indígena (Gómez Acuña, 2012, pp. 146-154) y alterna a la propuesta por Mariátegui en su prólogo a Tempestad en los Andes (1927). Una vuelta de tuerca más a la utopía retrospectiva de Una Lima que se va, de Gálvez (1921), que no conseguía evitar la pérdida de algunos rasgos viejos del criollismo en el túnel del olvido. No obstante, en las tres décadas que van de Leguía a Odría la fisonomía de barrios antiguos como Rímac, Malambito, Monserrate, Barrios Altos resultó mucho menos afectada. Se mantuvo el trazado secular en cuadrícula con calles estrechas de nombre virreinal (Pilitriki, Siete Jeringas, Matajudíos, Faltriquera del Diablo, Polvos Azules, Yaparió, etcétera) hasta la segunda mitad del siglo $\mathrm{XX}$, denominaciones arcaicas indicadoras de una recordación transmitida mediante una rica comunicación oral. Luis Millones (1978, p. 44) nos recuerda que "durante siglos los nichos urbanos de miseria estuvieron informados de valores serviles coloniales, [lo cual] ha determinado que se desarrollen formas culturales propias en este extremo de la escala social". Esa especificidad fue el caldo de cultivo en el que los rasgos de la picaresca española de muchos peninsulares que vivían de la ingenuidad de los otros (¿origen de la 'viveza' criolla?) renuentes al trabajo manual por no ser 'de caballeros' (siendo desclasados), se combinaron con las burlas a la ley de los cimarrones y libertos confundidos entre la gente ociosa de la ciudad. Algunos aspectos de este fenómeno intercultural generado en el mundo popular lograron cierto grado de cristalización y durabilidad en una ciudad cuya población había crecido relativamente poco hasta entrado el siglo XX y devenir en un conjunto compartido de representaciones colectivas (Millones, 1978, pp. 45-46). ¿Subyace a estos rasgos una estructuración que permita hablar del criollismo como de una 'cultura'? Si nos ponemos en el tiempo de las mentalidades de larga duración sin ninguna duda, siempre y cuando se le perciba en tanto repertorio simbólico fragmentado y de bordes variables según la época y el espacio social. Más precisamente, se puede ser criollo por momentos, no todo el tiempo; el criollismo es un actuar, una sociabilidad particular. 
De entre las diversas manifestaciones del criollismo me parece más pertinente referirme al vals, consagrado como género musical capitalino por antonomasia durante su esplendor. En esa música se conjugan intensas emociones despertadas en su ejecución y escucha que hacen aflorar ánimos contagiosos sobre espacios reconocidos y compartidos como propios. De hecho, construye simbólicamente a la urbe de esa época, la inviste de ciertas cualidades que la hacen única y memorable. La letra es un aspecto insoslayable del vals criollo que 'ancla' la ejecución musical en la narración declamada por quien canta e instaura un imaginario compartido, cuyos colores afectivos son las vivencias de la vida urbana. Las letras cantadas son además indicadoras de cierto relato vital de época, posteriormente sedimentado como elemento primordial del imaginario criollo limeño: el fatalismo y la muerte. Las imágenes del sufrimiento, la pérdida amorosa, la exaltación de lo femenino - por un enunciador invariablemente masculino - han remitido por mucho tiempo a significados fúnebres: el cuerpo de la amada muerta, el guardián del cementerio, la noche con su 'negro crespón'. Más allá de los bríos de las luchas políticas y de la alegría de las jaranas se adivina en la cuarta y quinta década del siglo XX cierto fatalismo guardado in pectore, permeable a la seducción de lo tanático. Las familias pobres solían compartir el hecho común de muertes tempranas, recogido en el acervo criollo como ocurre con el vals El tísico, aparecido en la década de 1940 y cantado en la siguiente por Los Embajadores Criollos (Pamo, 2014, p. 152). Dicho de otro modo, esas expresiones culturales arrebataron a la ciudad de su condición de materia inánime y ahistórica y se convirtieron en parte de ella, la encarnaron. Donde había escasez de escucha (p. e. falta de medios de reproducción), la música fue (es) frecuentemente actuada, una ocurrencia colectiva, acompañada de ejecución instrumental, canto, baile, bebida y seducción: la jarana. La singularidad de cada ocasión de goce musical estaba relacionada con la falta de registro sonoro y de reproducción, como ocurrió hasta fines del siglo XIX cuando progresivamente las invenciones propiciaron una revolución musical limeña que expresaba mejor las sensibilidades de sus habitantes que la modernización urbanística.

Gracias a la radiodifusión, el vals vino a ser una especie de banda sonora de la vida limeña. La radio funcionó como un dispositivo de comunicación para un área cuya extensión ya impedía recorrerla a pie y en la cual resultaba imposible a sus habitantes conocerse entre sí, aunque sea de vista. La gran virtud de este medio era generar oralmente sentidos sobre aquello que fuese del interés cotidiano de la mayoría. Por su naturaleza vocal el medio resultó inevitablemente educativo, pues contribuyó a difundir léxicos, hablas, fonéticas y eventualmente costumbres antes ajenas entre sí.

El nacimiento de la radiodifusión demarca un límite entre el vals de los primeros tiempos y aquel consolidado para una audiencia ampliada con este medio de comunicación. Fred Rohner ha estudiado este desplazamiento basándose en la obra de Felipe 
Pinglo, y escribe con ironía (2015, p. 75): “Si algo caracteriza a la Guardia Vieja es la modernidad", pues esta denominación genérica del repertorio de valses apareció para diferenciar a la generación de músicos ingresada al mercado de la reproducción discográfica con respecto a la precedente, que en muchos casos fue pasando al anonimato o al olvido. No fue una modernización uniforme; aunque el desarrollo de la radio convergió con esa expansión, su acceso tardó en alcanzar un público mayoritario. La primera emisora radial, la OAX (1925), terminó en un fiasco por falta de oyentes. Solo el $43 \%$ de los hogares capitalinos contaba con energía eléctrica según el censo de 1931, según detalla Emilio Bustamante (2012, p. 128). Por ello solo a partir de 1936 -irónicamente el año del deceso de Felipe Pinglo- se hace fuerte la música criolla, particularmente a través de la flamante Radio Nacional (Bustamante, 2007, p. 171), fundada un año después sobre la base de la antigua OAX, aunque el rechazo de las clases altas hacia el vals se prolongó hasta los años 1950.

La canción criolla en la radio y el disco fueron el punto de inicio de un largo hilo conductor del acervo musical popular que conduce hasta el presente siglo. Las adaptaciones y fusiones, así como la inclusión en el transcurso del tiempo de géneros musicales populares extranjeros a través de otros medios -y hoy de nuevas plataformas- ha esfumado ese origen, pese a que después se siguió traduciendo una lógica cultural similar. Lo importante ha sido cómo por tres décadas se cristalizó un gusto artístico propio y nuevo que condensó paulatinamente los sentidos comunes de casi toda la ciudad. Cuando ya superaba el millón y medio de habitantes en los años 50, medio Lima bailaba las composiciones de Chabuca Granda, gente de abajo y arriba. La urbe ingresaba a su condición de metrópoli con una morfología moderna que fue quizá la más ordenada del siglo. La violencia del conflicto interno, la frustración social y económica arrastrada desde mediados de la década de 1970 hasta la última del siglo contrastó con tres décadas de urbanización postcolonial acompañadas de cierta 'occidentalización' cultural. La mirada retrospectiva deja la sensación de haber vivido la ilusión de una 'modernidad periférica', en un sentido semejante al que Beatriz Sarlo (2003) elabora al caracterizar a Buenos Aires, "un periodo de incertidumbres, pero también de seguridades muy fuertes, de relecturas del pasado y utopías, donde la representación del futuro y del pasado chocan" (p. 29).

La sobreabundancia actual de imágenes del presente ha oscurecido ese pasado. La iconografía y los testimonios escritos o sonoros al alcance del ciudadano promedio son escasos. Escasearon los pintores notables de Lima de aquel periodo. Los más recordados se volcaron hacia temas indigenistas, como ocurrió con Julia Codesido, José Sabogal, Enrique Camino Brent, y en menor medida, Jorge Vinatea Reinoso. Prácticamente no hubo expresionismo, salvo Sérvulo Gutiérrez, pero no dejó mucho de la ciudad en su obra. Quizá Víctor Humareda haya sido tardíamente su cultor más 


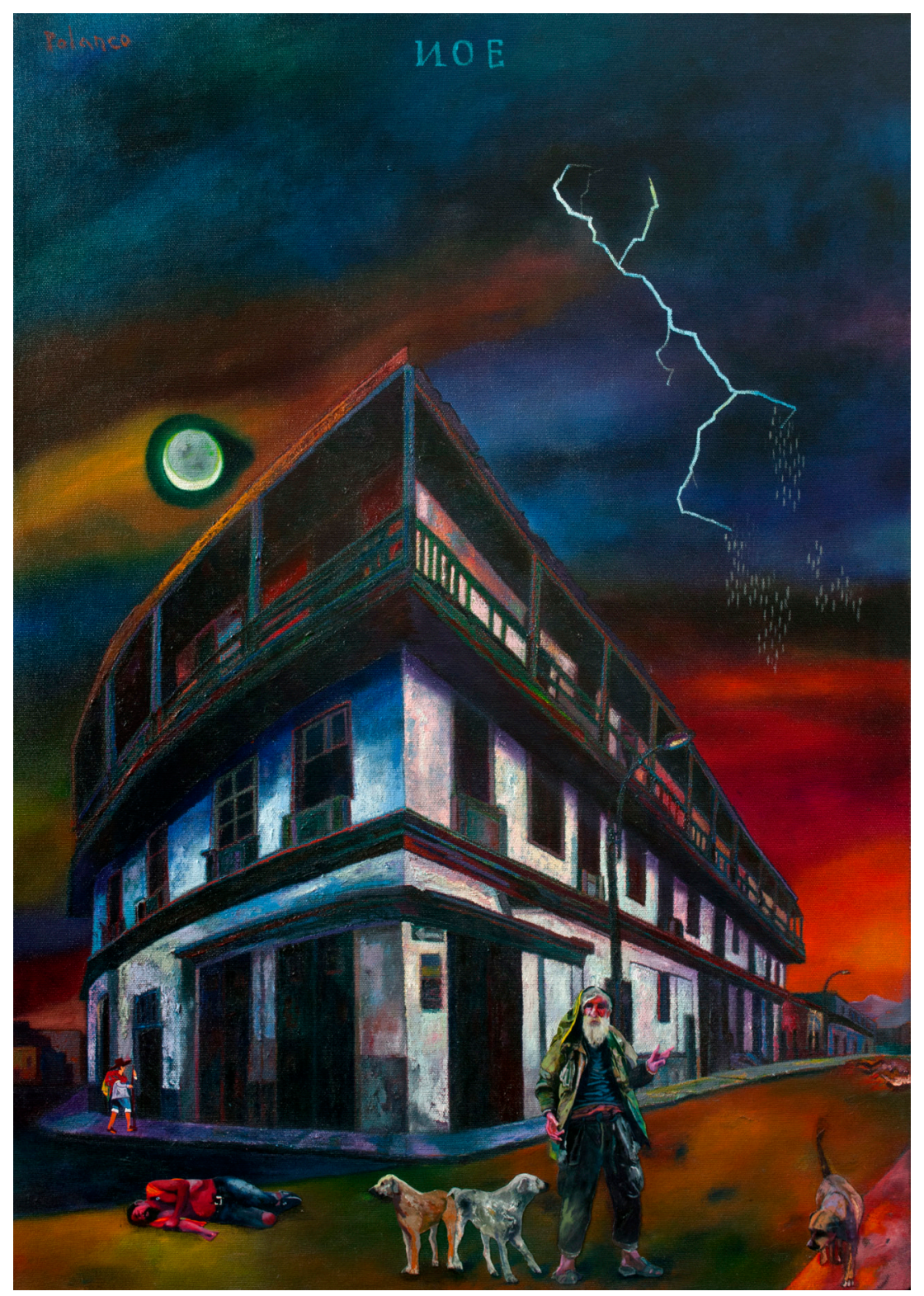

Enrique Polanco. Pasacalle (El Buque) (2013). Óleo sobre tela, 1,20 m x 1 m. Después de su destrucción le debemos mucho a Polanco por haberlo conservado como muchos lo soñamos.

reconocido. Hoy los colores intensos de Enrique Polanco componen una escenificación única, mezcla del humor y del drama de esa Lima de hace más de medio siglo. Casi no hay novela urbana. Habría que ir más atrás, hasta el Duque o la Suzy de José Diez Canseco y la barranquina Casa de cartón de Martín Adán, quien a sus veinte años ya sabía que "aquí, en este suelo fofo y duro, a manchas, yacen las casas futuras de la ciudad, con sus azoteas entortadas, sus ventanas primorosas de yeso, con sus salas con victrola y sus secretos de amor" (2006 [1928], p. 113) o quizá más adelante, al fin 
del periodo, y llegar a Julio Ramón Ribeyro, que empieza a escribir a principios de los años 1950, o Enrique Congrains, figuras aisladas y ya de otra generación.

\section{MEMORIA PERDIDA Y CAOS URBANO}

Ese proyecto de identidad urbana no siempre explícito que desbordó fronteras ideológicas se vio interrumpido en pocos años cuando la ya existente migración interna llegó a extremos hipertróficos. En la década de 1950 se inauguró una larga era de heterogeneidad habitacional e hibridaciones culturales. La desigualdad se reflejó en un nuevo modo de edificación material de la ciudad y de producción simbólica de lo urbano. ¿Fue esto una fatalidad? Por supuesto, si por ello entendemos un encuentro inexorable con la realidad de transformaciones profundas, inesperadas e irreversibles, fruto de una evolución previamente soslayada. Para la capital peruana de mediados del siglo pasado fue una triple conjunción: la incorporación del país al galopante capitalismo de posguerra, la presión demográfica sobre la sierra, seguida de su empobrecimiento, y la apertura de carreteras hacia la costa. Tras habérseles dado la espalda a lo largo de prácticamente toda la historia republicana, las economías andinas languidecieron, y los oceánicos arribos a la capital equivalían, sin serlo, a su desquite histórico. Los asentamientos de inmigrantes avivaron la mezcla de arrogancia y temor del racismo limeño.

Quizá cada época engendra las utopías retrospectivas que se merece, pero en este nuevo siglo los limeños seguimos padeciendo ese déficit de gobernanza. La urgencia por atender los problemas del presente y el afeamiento de la ciudad -aunque decirlo sea políticamente incorrecto- nos hacen olvidar que hubo una época distinta. Lejos de la nostalgia criolla, me refiero a una ciudad que ya era moderna hace medio siglo sin saber o poder enfrentar su crecimiento.

Para Sebastián Salazar Bondy, según escribió hace 55 años, en Lima la horrible (1964, p. 19):

donde dos millones de personas se dan de manotazos en medio de bocinas, radios salvajes, congestiones humanas y otras demencias contemporáneas ... el caos civil, producido por la famélica concurrencia urbana de cancerosa celeridad, se ha constituido, gracias al vórtice capitalino, en un ideal: el país entero anhela deslumbrado arrojarse en él, atizar con su presencia el holocausto del espíritu. 


\section{REFERENCIAS}

Adán, M. [Rafael de la Fuente Benavides] (2006 [1928]). La casa de cartón. Madrid: Signos.

Bustamante, E. (2007). Apropiaciones y usos de la canción criolla 1900-1939, Contratexto, 15,165188. Recuperado de http://revistas.ulima.edu.pe/index.php/contratexto/article/view/ $779 / 751$

Bustamante, E. (2012). La radio en el Perú. Universidad de Lima, Fondo Editorial.

Calderón Cockburn, J. (2005). La ciudad ilegal. Lima en el siglo XX. Lima: Universidad Nacional Mayor de San Marcos.

Chuhué, R. (2016). Capón: el barrio chino. Municipalidad Metropolitana de Lima.

Diez-Canseco, J. (2004 [1930]). Suzy, en José Diez-Canseco, Narrativa completa 2. Lima: Pontificia Universidad Católica del Perú.

Drinot, P. (2016). La seducción de la clase obrera: trabajadores, raza y la formación del Estado peruano. Lima: Instituto de Estudios Peruanos / Ministerio de Cultura.

Gálvez, J. (1921). Una Lima que se va. Crónicas evocativas. Lima: Euforión.

Gálvez, J. (1966 [1930]). Nuestra pequeña historia. Lima: Universidad Nacional Mayor de San Marcos.

Gómez Acuña, L. (2007). Lo criollo en el Perú republicano. Breve aproximación a un término elusivo. Revista Histórica, 31(2). Lima: Pontificia Universidad Católica del Perú, Departamento de Humanidades.

Lauer, M. (1982). Crítica de la artesanía. Plástica y sociedad en los Andes peruanos. Lima: Desco.

Ludeña, W. (2003). Urbanismo moderno en el Perú. El aporte de la Agrupación Espacio. Aproximaciones. En Urbes. Revista de ciudad, urbanismo y paisajes. Año 1, n. 1. Lima: Wiley Ludeña Urquizo.

Ludeña, W. (2006). Barrio y ciudad: historiografía urbanística y la cuestión del dominio de referencia. El caso de Lima. En Bitácora 10 (1). Bogotá: UNAL.

Majluf, N. (1994). Escultura y espacio público. Lima 1850-1879. Lima: Instituto de Estudios Peruanos, Documento de Trabajo n. ${ }^{\circ} 67$.

Millones, L. (1978). Tugurios. La cultura de los marginados. Lima: Instituto Nacional de Cultura.

Miró Quesada, L. (2014 [1945]). Espacio en el tiempo, la arquitectura como forma cultural. Lima: Clásicos Peruanos. Arquitectura y pensamiento.

Molinari Morales, T. (2017). Dictadura, cultura autoritaria y conflicto político en el Perú (1936-1939). Lima: Universidad Nacional Mayor de San Marcos.

Pamo Reyna, O. (2014). La tuberculosis y el vals criollo en la ciudad de Lima de las primeras décadas del siglo XX. Revista de la Sociedad Peruana de Medicina Interna, 27(3). 
Panfichi, A. (2013). Sociología de los barrios populares del centro de Lima, siglo XX. En Aguirre, C. y Panfichi, A. (eds.) Lima, siglo XX. Cultura, socialización y cambio. Lima: Pontificia Universidad Católica del Perú.

Portocarrero, G. (ed.) (2013). La utopía del blanqueamiento y la lucha por el mestizaje, en Sombras coloniales y globalización en el Perú de hoy. Lima: Red para el Desarrollo de las Ciencias Sociales en el Perú.

Ramón, G. (2004). El guion de la cirugía urbana. Lima 1850-1940, en Ensayos en ciencias sociales. Lima: SISBIB - Universidad Nacional Mayor de San Marcos.

Rodríguez Pastor, H. (2008). Gastronomía chino-cantonesa y el chifa peruano. Gaceta Cultural del Perú, 32.

Rohner, F. (2015). Una aproximación a la generación de Felipe Pinglo: la Guardia Vieja y el rol de las industrias culturales en la configuración del canon musical criollo, en E. Romero, (ed.) Música popular y sociedad en el Perú contemporáneo. Lima: Pontificia Universidad Católica del Perú. Instituto de Etnomusicología.

Salazar Bondy, S. (1964). Lima la horrible. Lima: PEISA.

Sarlo, B. (2003). Una modernidad periférica. Buenos Aires 1920 y 1930. Buenos Aires: Nueva Visión.

Silva, A. (1992). Imaginarios urbanos. Bogotá y Sao Paulo: Cultura y comunicación urbana en América Latina. Bogotá: Tercer Mundo.

Simmel, G. (2003 [1902]). The Metropolis and Mental Life, en Ch. Harrison, y P. Wood, Art in Theory, 1900-2000. Londres: Blackwell Publishing.

Stein, S. (1980). Populism in Peru. The emergence of the Masses and the Politics of Social Control. Madison: The University of Wisconsin Press.

Zapata, A. (1990). Chalet y material noble: las mentalidades sobre la vivienda en la Lima del siglo XX, en Tiempos de ira y amor. Nuevos actores para viejos problemas. Lima: Desco. 